\title{
A HETEROGENEIDADE ENUNCIATIVA EM ARTIGOS CIENTÍFICOS: UMA REVISÃO DE LITERATURA A PARTIR DO PORTAL DE PERIÓDICOS DA CAPES
}

\author{
Enunciative Heterogeneity In Scientific Articles: A Literature Review From Capes \\ Periodic Portal
}

Heterogeneidad Enunciativa En Artículos Científicos: Una Revisión De La Literatura Del Portal Periódico De Capes

\author{
Rodrigo Cavalcanti da Rocha ${ }^{1}$ \\ ${ }^{1}$ Mestrando em Linguística Aplicada pela Universidade de Taubaté - Unitau
}

*Correspondência: UNITAU - Pró-reitoria de Pesquisa e Pós-graduação - Secretaria do Mestrado em Linguística Aplicada. Rua Visconde do Rio Branco, 210 - Centro Taubaté - SP CEP: 12020-040 - Tel.: (12) 3624-1657. e-mail rodrigo.rover@gmail.com.

Artigo recebido em 16/10/2019 aprovado em 17/03/2020 publicado em 27/03/2020.

\section{RESUMO}

O presente trabalho apresenta dados decorrentes de revisão bibliográfica, pesquisa também chamada de "estado da arte", da produção científica que tem como referencial teórico o conceito de "Heterogeneidade Enunciativa", conforme dado pela linguista francesa Jacqueline Authier-Revuz. O objetivo é verificar como este tema tem sido tratado nas produções acadêmicas publicadas no Brasil nos últimos 20 anos. Para tanto, foi realizada busca no Portal de Periódicos da Coordenação de Aperfeiçoamento de Pessoal de Nível Superior (CAPES), do conceito "heterogeneidade enunciativa", entre aspas. Estes textos foram catalogados: seus autores, títulos e veículo responsável pela publicação foram listados, bem como seu resumo, a linha teórica que seguem e seu link eletrônico para acesso. Os procedimentos metodológicos seguiram a seguinte dinâmica: os textos selecionados foram separados em função da forma de abordagem da HE. Em seguida, foram lidos os resumos e as introduções de todos os trabalhos para extração de informações relacionadas ao uso da HE como referencial teórico. Como referência nota-se que em grande parte dos trabalhos pesquisados a HE tem sido mostrada como um campo de estudo dentro da Análise do Discurso de linha Francesa, a partir de Michel Pêcheux e sua obra "Semântica e Discurso", embora existam pesquisas que tratem este conceito como algo mais abrangente, até por dialogar com outras áreas fora do campo dos estudos da linguística aplicada.

Palavras-chave: Heterogeneidade Enunciativa. Dialogismo. Estado da Arte.

\section{ABSTRACT}

The present work presents data from a literature review, a research also called "state of the art", from the scientific production that has as theoretical reference the concept of "Enunciative Heterogeneity" (EH), as given by the French linguist Jacqueline Authier-Revuz. The objective is to verify how this theme has been treated in the academic productions published in Brazil in the last 20 years. For that, a search was made in the Portal of Periodicals of the Coordination of Improvement of Higher Level Personnel (CAPES), of the concept "enunciative heterogeneity", in quotation marks.These texts were cataloged: their authors, titles and vehicle responsible for the publication were listed, as well as their abstract, the theoretical line they follow and their electronic link for access. The methodological procedures followed the following dynamics: the selected texts separated according to the approach of EH. Next, the abstracts and the introductions of all the works extracted to extract information related to the use of EH as theoretical reference. As a reference it is noted that in a large part of the researches, HE has been shown as a field of study within the Analysis of the French Speech Discourse, from Michel Pêcheux and his work "Semantics 
and Discourse", although there are researches that deal this concept as something more comprehensive, even by dialoguing with other areas outside the field of applied linguistics studies.

Key-words: Enunciative Heterogeneity. Dialogism. State of art.

\section{RESUMEN}

Este artículo presenta datos de una revisión de literatura, una investigación también llamada "estado del arte", de la producción científica que tiene como referencia teórica el concepto de "heterogeneidad enunciativa", tal como lo dio la lingüista francesa Jacqueline Authier-Revuz. El objetivo es verificar cómo se ha tratado este tema en las producciones académicas publicadas en Brasil en los últimos 20 años. Para ello, se realizó una búsqueda en el Portal de Revistas de la Coordinación para el Mejoramiento del Personal de Educación Superior (CAPES), por el concepto "heterogeneidad enunciativa", entre comillas. Estos textos fueron catalogados: se enumeraron sus autores, títulos y vehículos responsables de la publicación, así como su resumen, la siguiente línea teórica y su enlace electrónico de acceso. Los procedimientos metodológicos siguieron las siguientes dinámicas: los textos seleccionados se separaron de acuerdo con el enfoque HE. Luego, leemos los resúmenes y las introducciones de todos los trabajos para extraer información relacionada con el uso de HE como marco teórico. Como referencia, se observa que en la mayoría de los estudios investigados, HE se ha demostrado como un campo de estudio dentro del Análisis del Discurso de la línea francesa, de Michel Pêcheux y su trabajo "Semántica y Discurso", aunque hay investigaciones que tratan sobre este concepto como algo más amplio, incluso al dialogar con otras áreas fuera del campo de los estudios de lingüística aplicada.

Descriptores: heterogeneidad enunciativa. Dialogismo Estado del arte.

\section{INTRODUÇÃO}

O presente trabalho apresenta dados decorrentes de revisão bibliográfica da produção científica que tem como referencial o conceito de "Heterogeneidade Enunciativa" (doravante HE) conforme descrito pela linguista francesa Jacqueline Authier-Revuz (1990, 2004). Para Authier-Revuz (1990), a HE pode ser mostrada explicitamente no discurso ou como elemento constitutivo, implícito, portanto, deste discurso. O desejo de usar este conceito como ferramenta de pesquisa ocorre porque, ainda de acordo com a autora, ele dialoga diretamente com os princípios de Mikhail Bakhtin (notadamente o dialogismo e a alteridade) e a psicanálise conforme Jaques Lacan.

A questão chave que guia esta pesquisa é: qual o tratamento que este referencial teórico recebe pelas pesquisas publicadas no Brasil? Este trabalho tem por objetivo oferecer um recorte representativo a partir da análise dos resultados obtidos não apenas de uma publicação ou conjunto de publicações, mas de artigos indexados em portal vinculado ao Ministério da Educação, pois este agrupa produções do país todo.

Interessa sobretudo a bibliografia acadêmica brasileira entre os anos de 2004 e 2018. Para tanto, foi realizada busca no Portal de Periódicos da Coordenação de Aperfeiçoamento de Pessoal de Nível Superior (CAPES), do conceito "heterogeneidade enunciativa", entre aspas. Foram catalogados 26 artigos, dispostos em quadro demonstrado dentro deste artigo. Foram selecionados para esta pesquisa, inicialmente, 38 artigos. Estes textos foram catalogados em uma planilha de dados onde eram identificados os títulos, os autores, a publicação responsável pelo artigo, seu resumo, a linha teórica que segue e seu link para acesso, caso necessário. Os procedimentos metodológicos seguiram a seguinte dinâmica: os textos selecionados foram separados em função da forma de abordagem da HE. Em seguida, foram lidos os resumos e as introduções de todos os trabalhos para extração de informações sobre o uso da HE como referencial teórico. 
Este trabalho representa uma possibilidade de contribuição para a pesquisa de revisão bibliográfica normalmente conhecida como estado da arte. Em sua organização estrutural este texto apresenta, além desta introdução, uma seção teórica, onde discutimos os conceitos lançados durante o texto, uma seção sobre a metodologia utilizada, onde aprofunda-se a questão do estado da arte como pesquisa científica, uma parte para a análise de excertos dos artigos compilados que utilizam a HE como aporte teórico, dispostas a partir de quadro que os identifique. E, por fim, a seção de conclusão.

\section{A HETEROGENEIDADE ENUNCIATIVA}

O conceito central deste artigo é o de Heterogeneidade Enunciativa (HE, nesta produção) conforme a linguista francesa Jaqueline Authier-Revuz (1990, 2008). Parte, em suas pesquisas, do que ela chama de "complexidade enunciativa" (1990), que envolve conceitos como "distanciamento, graus de comprometimento, desnivelamento ou deslocamento enunciativo, polifonia" (1990), onde questionava o caráter monódico da linguagem.

Como dito, a autora parte da perspectiva bakhtiniana da linguagem como um ente dialógico e da abordagem lacaniana da psicanálise, em particular sua releitura freudiana. Ou seja: a língua é algo que só se realiza atravessada por outros discursos, manifestada por um sujeito dividido, cuja fala é naturalmente heterogênea, o sujeito torna-se "efeito de linguagem", conforme Paula (2009). Como essa linguagem é até mesmo um processo de ressignificação do "já dito", resulta o demonstrado em Macedo (2016): as experiências vividas ou culturalmente assimiladas pelo sujeito retornam através de suas manifestações de linguagem.
Para Authier-Revuz, em seu artigo "Heterogeneidade(s) Enunciativa(s)", de 1990, dois são os caminhos da heterogeneidade no texto. A primeira é o que ela chama de heterogeneidade mostrada que inscrevem "o outro na sequência do discurso" (1990). O discurso direto, as aspas, discurso indireto livre, ironia, todas estas são formas que marcam a presença do outro no discurso. Esse fragmento, seja citado ou introduzido por termo metalinguístico, é marcado de forma nítida na cadeia discursiva e é apresentado como objeto.

Textualmente ou pelo interdiscurso, a primeira forma de heterogeneidade descrita aqui é aquela marcada. Altera a unicidade da cadeia discursiva para inserir o outro. Delimita o outro e, como assinala Authier-Revuz (1990), "segundo modalidades diferentes, com ou sem marcas de ancoragem."

A segunda forma de heterogeneidade é a chamada constitutiva. Além da introdução deste outro no discurso de forma linguisticamente marcada, explícita, Authier-Revuz (1990) observa ainda que a heterogeneidade também pode acontecer onde o "fragmento designado como um outro é integrado à cadeia discursiva sem ruptura sintática”. Ou seja: não há elemento linguístico que formalize a introdução do outro no texto; sua presença não está textualmente marcada. Aqui a heterogeneidade se faz remetendo-se ao exterior do discurso, em perspectiva dialógica afinal, fala-se sempre a palavra do outro para que o discurso seja dito. O discurso é produzido no e pelo interdiscurso.

São formas não explícitas, não marcadas na superfície. Elas definem-se pela relação que o discurso mantém com outros discursos. Deliberadamente ou através do inconsciente que pode atuar sobre o discurso. Macedo (2016) aponta que o tempo e o momento do sujeito acabam sendo resgatados pela 
palavra: todos são nele, e ele é em todos. AuthierRevuz (1990, p.33) pontua que existe a "diluição, a dissolução do outro no um, onde este, precisamente aqui, pode ser enfaticamente confirmado, mas também pode se perder”. Authier-Revuz (2008) afunila esta definição: é a heterogeneidade onde há, em todo o discurso, uma exterioridade discursiva que o permeia e o constitui. Remete-se também à questão dialógica: as palavras não são novas, são carregadas de um "já dito". Falar é, portanto, entrar em relação dialógica com discursos outros.

Aqui, o que permite a referenciação deste discurso presente é ele ser localizável pelos traços do “já dito" e não assinalado por marcações, conforme Authier-Revuz (2008). Pontua ainda que é fora de toda estrutura que esta heterogeneidade é percebida pelo receptor. Reminiscência, clichê, várias são as possibilidades de relação interior $\mathrm{x}$ exterior em um discurso; várias as "modalidades do 'contato' fronteiriço entre interior(es) e exterior(es)". A autora ainda frisa como "essencial" o que ela chama de "grau de marcação do outro" (Authier-Revuz, 2008) para que se tenha razoavelmente delimitados os territórios do um e do outro.

A HE, portanto, está presente marcando os enunciados em seu interior e também em seu exterior. São, para a autora, "radicalmente heterogêneas", afinal:

Uma depende da representação e da intencionalidade, a outra é estritamente irrepresentável para o sujeito falante, do qual ela determina o dizer; e ela não é acessível também ao analista que pode, além disso, construir hipoteticamente, sobre bases históricas, e sobre aspectos parciais da memória discursiva na qual se produz um discurso.

AUTHIER-REVUZ, Jacqueline, 2008, p. 110
Tem-se, finalmente, um referencial teórico que estuda e referencia os elementos do discurso: seus sujeitos, seus enunciados, suas marcações dentro e fora do texto, bem como seus discursos sejam eles formadores ou opositores. Como afirma Martins (2006), o discurso já é naturalmente dialógico, nessa relação que orienta a estrutura de qualquer discurso, construindo uma espécie de plurivalência de sentidos em que cada discurso se orienta para e por outros discursos. Não há necessariamente apenas marcadores linguísticos para evidenciar essas relações com a linguagem (ou mesmo DE linguagem) mas ela é, na verdade, "amparada pelos pressupostos psicanalíticos do discurso atravessado pelo inconsciente, pelo interdiscurso e pela orientação dialógica de todo discurso" (Martins, 2006). Eis a grande validade da HE para os estudos da linguagem: ela atravessa, conversa, desconstrói ou mesmo reconstrói discursos não apenas pelos fenômenos de linguagem, mas também a partir da leitura e caracterização de seus sujeitos que dela fazem uso.

\section{O ESTADO DA ARTE COMO METODOLOGIA DE TRABALHO}

As pesquisas científicas denominadas de "estado da arte" são, inicialmente, pesquisas de caráter essencialmente bibliográfico. Trata-se de revisão de literatura a respeito de determinado tema, com função primordial de investigar este determinado tema no contexto determinado da produção científica.

A seleção da bibliografia tem papel determinante em qualquer pesquisa de caráter científico que se proponha. Neste caso, em que é proposta uma revisão bibliográfica sobre o tema, ela torna-se não só protagonista, mas metodologia do trabalho em si. A bibliografia como técnica, conforme Severino (2002), tem por objetivo descrever e 
classificar livros e documentos a partir de critérios como autor, gênero, tema, data, entre outras possibilidades a partir da intenção do pesquisador.

A pesquisa desenvolvida neste artigo é, como já assinalado, bibliográfica. A ideia aqui apresentada é mapear como o conceito de Heterogeneidade Enunciativa tem sido estudado no Brasil a partir de levantamentos no portal de Periódicos da Coordenação de Aperfeiçoamento de Pessoal de Nível Superior (CAPES), fundação do Ministério da Educação. Este tipo de pesquisa pode ser chamado tanto como revisão bibliográfica, revisão de literatura ou, como chamada aqui, estado da arte.

Ferreira (2002) afunila o termo como a pesquisa bibliográfica que procura mapear e discutir certa produção acadêmica em determinada área do conhecimento. Revela ainda seu caráter descritivo e inventariante, de modo a perceber aspectos $\mathrm{e}$ dimensões acerca do escopo pesquisado. Aponta também os catálogos como fonte documental inicial do processo, em particular os "os catálogos de faculdades, institutos, universidades, associações nacionais e órgãos de fomento da pesquisa" (Ferreira, 2002).

Já Romanowski e Ens (2006) apontam que as pesquisas de estado da arte configuram importante contribuição na construção do campo teórico, pois:

Procuram identificar os aportes significativos da construção da teoria e prática pedagógica, apontar as restrições sobre o campo em que se move a pesquisa, as suas lacunas de disseminação, identificar experiências inovadoras investigadas que apontem alternativas de solução para os problemas da prática e reconhecer as contribuições da pesquisa na constituição de propostas na área focalizada.

ROMANOWSKI, Joana Paulin e ENS, Romilda Teodora, 2006, p. 40.
Da forma como exposto, o que se tem é um campo teórico cada vez mais sedimentado e referenciado para pesquisas, o que ajuda a ampliar o leque de possibilidades de estudo. As pesquisas de estado da arte, portanto, tem contribuição importante para os estudos acadêmicos.

\section{A \\ HETEROGENEIDADE \\ COMO \\ REFERENCIAL TEÓRICO: O QUE REVELAM OS ARTIGOS PESQUISADOS NO PORTAL DE PERIÓDICOS DA CAPES}

Este artigo trata-se de uma pesquisa de estado da arte acerca da Heterogeneidade Enunciativa (HE) a partir do conceito dado por Jacqueline Authier-Revuz. O levantamento foi feito a partir de busca pelo tema, entre aspas, no portal de periódicos da Capes, vinculada ao ministério da Educação. Foram agrupados artigos escritos nos últimos 20 anos - a partir do ano de 2000, portanto. A ideia é traçar um panorama de como o tema tem sido estudado nas pesquisas brasileiras neste século XXI: como ele tem sido abordado e, como referencial teórico que é, quais temas a heterogeneidade enunciativa tem subsidiado como fundamentação teórica principal ou como ferramenta de análise.

Algumas pesquisas tratam a HE como aporte da Análise do Discurso (AD) de linha francesa, como uma terceira fase desta linha teórica tendo como referência os estudos discursivos de Michel Pecheux. Outras pesquisas relacionam com a $\mathrm{AD}$ vinculada aos estudos da linguagem de Mikhail Bakhtin. Entretanto, não raro, encontramos artigos que tratam a HE como campo de estudo autêntico e autônomo, dentro dos estudos da linguagem.

A partir dos primeiros 38 artigos selecionados, foram eliminados aqueles em que havia menção ao termo "Heterogeneidade Enunciativa", porém sem relação direta com a linha de pesquisa aqui 
adotada. No aspecto da linha teórica, os artigos foram divididos conforme abordagem listada no parágrafo anterior: $\mathrm{AD}$ de linha francesa (a partir de Pecheux), AD dialógica (a partir de Bakhtin) e a própria HE como referencial teórico principal. Este primeiro filtro fez a pesquisa cair para 28 artigos.

Como o foco deste estudo são os postulados de Jacqueline Authier-Revuz, foram eliminados artigos em que, apesar do termo heterogeneidade enunciativa ter sido citado, o nome da linguista francesa não constava como referência teórica fundamental - em alguns casos, sequer constava entre as referências bibliográficas. Em alguns casos, onde a teoria da linguista francesa era citada, ela servia apenas em determinado ponto do texto, em caráter localizado dentro das AD citadas no parágrafo anterior. Outras, em pesquisas completamente diferentes. Isto se deu, por exemplo, em casos onde eram pesquisadas as questões sobre "enunciados" ou mesmo o conceito de heterogeneidade voltada aos estudos biológicos, nas questões de gênero. Este refino fez o campo de análise cair para os 13 artigos aqui compilados.

Foram compilados artigos das seguintes publicações, com os seguintes títulos:

Quaadro 1 - Compilação dos artigos analisados nesta pesquisa.

\begin{tabular}{|c|c|c|c|}
\hline $\mathbf{N}^{\circ}$ & Publicação & Título & Autores \\
\hline 1 & $\begin{array}{l}\text { Revista de Letras - Centro de } \\
\text { Humanidades }- \text { Universidade } \\
\text { Federal do Ceará/UFC - } \\
\text { Fortaleza-CE }\end{array}$ & $\begin{array}{l}\text { "Apelo a um exterior: as alusões } \\
\text { como estratégias argumentativas" }\end{array}$ & $\begin{array}{l}\text { Mariza Angélica Paiva Brito } \\
\text { Maria Dayanne Sampaio Falcão } \\
\text { José Elderson de Souza Santos }\end{array}$ \\
\hline 2 & $\begin{array}{l}\text { Fórum Linguístico, Florianópolis, } \\
\text { v. } 11 \text {, n. } 4 \text {, p.444-456, out./dez. } \\
2014\end{array}$ & $\begin{array}{l}\text { O discurso de formandos do curso } \\
\text { de Letras: "Falta coesão, falta } \\
\text { coerência no texto de uma menina } \\
\text { de } 10 \text { anos!" }\end{array}$ & Orlando de Paula \\
\hline 3 & $\begin{array}{l}\text { Linguagem em (Dis)curso, 2007, } \\
\text { Vol.7(1) }\end{array}$ & $\begin{array}{l}\text { Heterogeneidade enunciativa no } \\
\text { discurso sobre o ambiente na } \\
\text { imprensa } \\
\text { funcionamento e efeitos do } \\
\text { discurso directo }\end{array}$ & Rui Ramos \\
\hline 4 & $\begin{array}{l}\text { Alfa: Revista de Lingüística, } 01 \\
\text { January 2005, Vol.49(1) }\end{array}$ & $\begin{array}{l}\text { Heterogeneidade em narrativas } \\
\text { escolares: sentidos que se } \\
\text { constroem nas diferenças e nos } \\
\text { desvios }\end{array}$ & Maria Madalena Borges Gutierre \\
\hline 5 & $\begin{array}{lll}\text { ESPecialist, } & \text { 2003, } & \text { Vol.24, } \\
\text { pp.167-184 } & & \end{array}$ & $\begin{array}{l}\text { Discurso relatado como estratégia } \\
\text { organizadora da notícia }\end{array}$ & $\begin{array}{llll}\text { Sant'Anna, Vera Lúcia } & \text { De } \\
\text { Albuquerque } & & & \end{array}$ \\
\hline 6 & $\begin{array}{l}\text { Bakhtiniana: Revista de Estudos } \\
\text { do Discurso, } 01 \text { June 2013, } \\
\text { Vol.8(1), pp.220-232 }\end{array}$ & $\begin{array}{l}\text { O discurso citado na construção } \\
\text { do ethos: análise discursivo- }\end{array}$ & $\begin{array}{l}\text { Piris, Eduardo Lopes; } \\
\text { Nascimento, Darling Moreira Do }\end{array}$ \\
\hline
\end{tabular}




\begin{tabular}{|c|c|c|c|}
\hline & & $\begin{array}{l}\text { argumentativa de O país do } \\
\text { carnaval, de Jorge Amado }\end{array}$ & \\
\hline 7 & $\begin{array}{l}\text { DELTA: Documentação de } \\
\text { Estudos em Lingüística Teórica e } \\
\text { Aplicada, January 2011, } \\
\text { Vol.27(1), pp.121-145 }\end{array}$ & $\begin{array}{l}\text { Vozes em embate na mídia de } \\
\text { informação e produção da } \\
\text { objetividade: polêmicas em torno } \\
\text { da precarização do trabalho na } \\
\text { escola }\end{array}$ & Deusdará, Bruno; Rocha, Décio \\
\hline 8 & $\begin{array}{l}\text { Linguagem em (Dis)curso, 2007, } \\
\text { Vol.7(1) }\end{array}$ & $\begin{array}{l}\text { A interincompreensão gera } \\
\text { polêmica: alteridade } \\
\text { heterogeneidade nos discursos das } \\
\text { cantoras Anitta e Pitty sobre } \\
\text { comportamento sexual feminino }\end{array}$ & Ramos, Rui \\
\hline 9 & $\begin{array}{l}\text { e-Hum: Revista das Áreas de } \\
\text { Humanidade do Centro } \\
\text { Universitário de Belo Horizonte, } \\
01 \text { December 2018, Vol.11(1), } \\
\text { pp.8-28 }\end{array}$ & $\begin{array}{l}\text { Análise enunciativa do discurso de } \\
\text { divulgação científica na mídia } \\
\text { impressa }\end{array}$ & Jairo Venício Carvalhais Oliveira \\
\hline 10 & $\begin{array}{l}\text { Signótica, 2005, Vol.17(2), } \\
\text { pp.232-250 }\end{array}$ & $\begin{array}{l}\text { Mais de perto, mil faces secretas } \\
\text { sob a face neutra: considerações } \\
\text { sobre a heterogeneidade no } \\
\text { discurso jornalístico }\end{array}$ & Sousa Romao, Lucília Maria \\
\hline 11 & $\begin{array}{l}\text { DELTA: Documentação de } \\
\text { Estudos em Lingüística Teórica e } \\
\text { Aplicada, January 2006, } \\
\text { Vol.22(2), pp.303-328 }\end{array}$ & $\begin{array}{l}\text { O cavalete, a tela e o branco: } \\
12 \text { introdução à autoria na rede } \\
\text { eletrônica }\end{array}$ & Romão, Lucília Maria Sousa \\
\hline 12 & $\begin{array}{l}\text { Veredas - Revista de Estudos } \\
\text { Linguisticos, July, } 2010 \text {, } \\
\text { p.130(12) }\end{array}$ & $\begin{array}{l}\text { As heterogeneidades enunciativas } \\
\text { como aporte teórico-metodológico } \\
\text { para a Análise do Discurso de } \\
\text { linha francesa }\end{array}$ & $\begin{array}{l}\text { Diana Pereira Coelho De } \\
\text { Mesquita; Ismael Ferreira Rosa }\end{array}$ \\
\hline 13 & $\begin{array}{l}\text { Acta Scientiarum. Language and } \\
\text { Culture (UEM), 2017, Vol.39(2), } \\
\text { p.167(12) }\end{array}$ & $\begin{array}{l}\text { Deriva referencial em discursos } \\
\text { sobre a organização dos jogos } \\
\text { olímpicos de } 2016\end{array}$ & $\begin{array}{l}\text { Braga, Diego Vieira ; Cazarin, } \\
\text { Ercilia Ana }\end{array}$ \\
\hline
\end{tabular}

Estas publicações abordaram os seguintes aspectos dos estudos linguísticos: 


\section{Textos por referencial teórico}

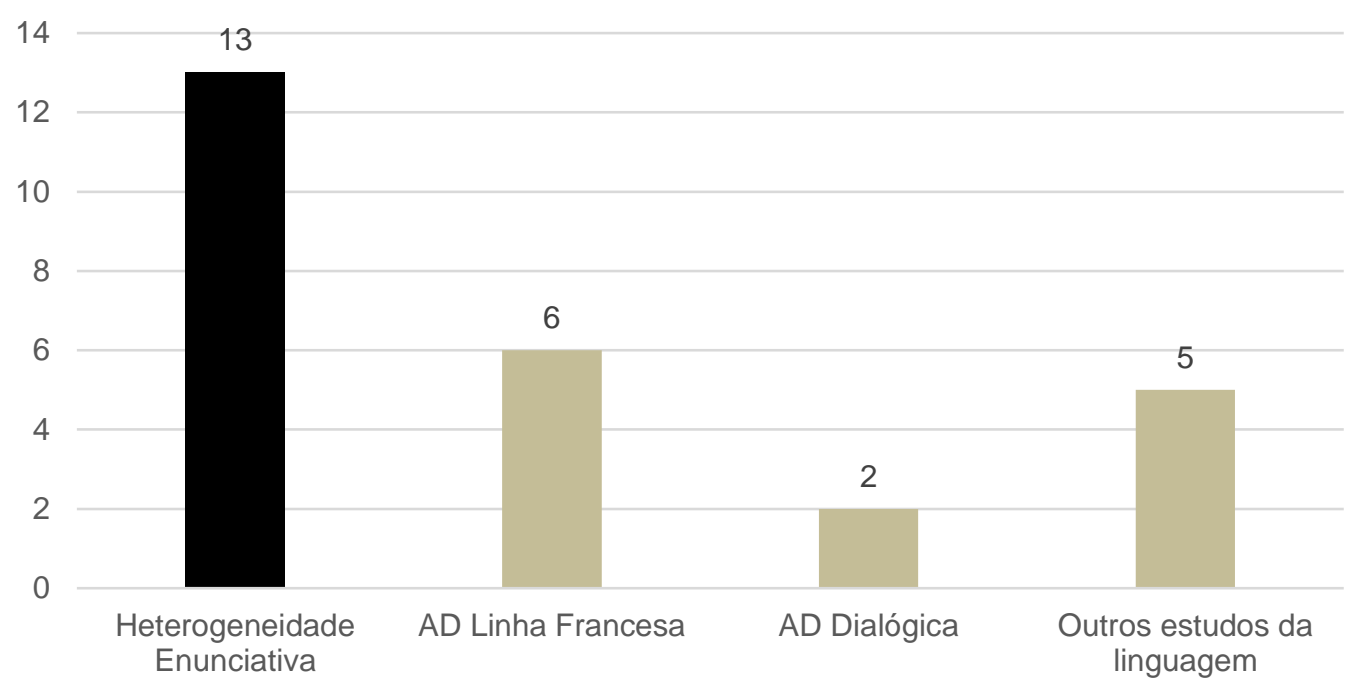

Dentro desta perspectiva, os artigos foram separados a partir do tratamento dado ao conceito de HE, conforme segue:

Quadro 2: Corpus de análise e respectivo referencial teórico dos artigos compilados

\begin{tabular}{|c|c|c|c|c|}
\hline \multicolumn{2}{|r|}{ Corpus de Análise } & \multirow[t]{2}{*}{$\begin{array}{l}\text { Heterogeneidade } \\
\text { Mostrada }\end{array}$} & \multirow[t]{2}{*}{\begin{tabular}{|c|} 
Heterogeneidade \\
Constitutiva
\end{tabular}} & \multirow{2}{*}{\begin{tabular}{|c|} 
Ambos \\
$\mathbf{X}$ \\
\end{tabular}} \\
\hline 1 & Alusões nos discursos em redes sociais (Facebook e Instagram) & & & \\
\hline 2 & Posicionamento discursivo formando dos cursos de Letras & $\mathbf{X}$ & & \\
\hline 3 & Discurso direto - manifestações da imprensa sobre meio ambiente & & $\mathbf{X}$ & \\
\hline 4 & $\begin{array}{l}\text { Produção de texto para SARESP (Sistema de Avaliação de Rendimento } \\
\text { Escolar do Estado de São Paulo) }\end{array}$ & & & $\mathbf{X}$ \\
\hline 5 & $\begin{array}{l}\text { Discurso relatado em notícias dos jornais Folha de S. Paulo e Clarin sobre } \\
\text { Mercosul }\end{array}$ & $\mathbf{X}$ & & \\
\hline 6 & $\begin{array}{l}\text { Discurso Citado e Ethos Discursivo em "O país do Carnaval" (Jorge } \\
\text { Amado) }\end{array}$ & $\mathbf{X}$ & & \\
\hline 7 & $\begin{array}{l}\text { Análise de Mídia impressa - notícias de jornal tematizando o Programa de } \\
\text { gratificação Nova Escola, instituído na rede pública estadual do Rio de } \\
\text { Janeiro }\end{array}$ & $\mathbf{X}$ & & \\
\hline 8 & Manifestações do discurso de imprensa sobre o meio ambiente. & $\mathbf{X}$ & & \\
\hline 9 & $\begin{array}{l}\text { Manifestação da alteridade em artigos de divulgação científica veiculados } \\
\text { na mídia impressa. }\end{array}$ & & & $\mathbf{x}$ \\
\hline 10 & Discurso jornalístico baseado nas condições de produção atuais & & & $\mathbf{X}$ \\
\hline 11 & $\begin{array}{l}\text { Autoria na rede eletrônica, focando especialmente a questão da memória, } \\
\text { do arquivo e do sujeito. Corpus linguístico coletado em 2004, em um blog } \\
\text { político de nome Mexidão }\end{array}$ & & & $\mathbf{x}$ \\
\hline 12 & $\begin{array}{l}\text { Como as heterogeneidades enunciativas constituíram-se como importante } \\
\text { aporte teórico-metodológico para o desenvolvimento da episteme da } \\
\text { Análise do Discurso de linha francesa }\end{array}$ & & & $\mathbf{x}$ \\
\hline 13 & $\begin{array}{l}\text { Sequências discursivas extraídas de declarações de Carlos Nuzman, } \\
\text { presidente do comitê organizador dos Jogos Olímpicos Rio } 2016\end{array}$ & & & $\mathbf{X}$ \\
\hline
\end{tabular}

Figura 2: Percentual para cada abordagem dos diferentes tipos de HE 


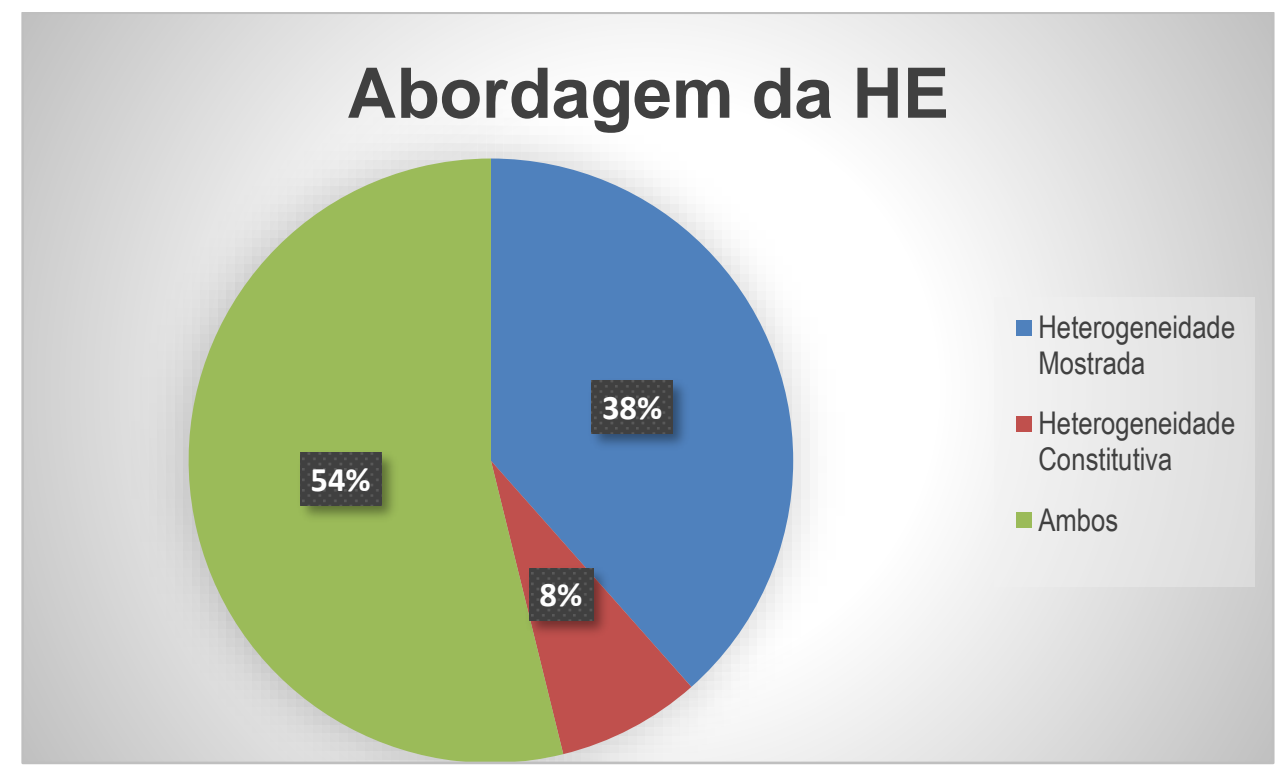

O primeiro padrão de abordagem que chama a atenção é que grande parte dos textos direciona a questão da $\mathrm{HE}$ em ambas as formas. A leitura dos textos que fazem parte do corpus desta pesquisa permite a inferência de que a HE é usada como um campo autônomo, em que formas mostradas ou enunciativas se completam, referenciam-se na busca de respostas linguísticas que envolvam a questão entre enunciados, discursos e sujeitos.

Em sua forma mostrada, evidenciada ou não por mecanismos linguísticos explícitos no texto, ela ganha mais fôlego por ser de evidência mais explícita. Dos artigos pesquisados aqui, $38 \%$ usam as formas mostradas, seja, elas marcadas ou não. Mais de um terço dos textos utiliza esta possibilidade investigativa da HE em seus artigos, seja prioritária ou exclusivamente as formas mostradas. A possibilidade de heterogeneidade mais investigada, portanto, é aquela em que é evidenciada na materialidade textual, conforme apontam De Mesquita e Rosa (2010). As autoras também mencionam que há, neste caso, a “indicação na superfície do texto da presença de outros discursos, de outras vozes que não a do locutor" (De Mesquita e Rosa, 2010, p. 132).

A heterogeneidade marcada no discurso, portanto não marcada textualmente, aparece ainda quando se apontam questões sobre o discurso citado, ou discurso relatado. Sant'Anna (2003) indica que este tipo de discurso "consiste em uma das formas da heterogeneidade mostrada do discurso, isto é, o conjunto de formas linguísticas que inscrevem o outro na sequência do discurso" (Sant'Anna, 2003, p. 230). Portanto, coube bem ao propósito deste artigo de analisar o discurso citado em publicações de mídia impressa.

Ainda na abordagem midiática, a heterogeneidade enquanto "negociação com a fala do outro" (Deusdará e Rocha, 2001, p. 122) aparece também na pesquisa sobre a atuação dos profissionais da Educação no ensino médio publicada por Bruno Deusdará e Décio Rocha em 2001. Os resultados demonstraram que o discurso tornado como narrativa criaram efeito de objetividade nas vozes captadas. Também adota o discurso relatado como corpus, os autores pontuam a existência de um embate em que

A atribuição de um relato a outro vem colocar em cena uma luta do discurso para delimitar a presença do outro em um determinado ponto, em uma extensão localizável, presença essa que, em última instância, contrariamente a tal representação, o constitui integralmente. Nesse embate, que produz como resultado a ilusão de uma 
suposta fronteira entre um discurso e seu outro, é possível recuperar sistemas de referência que evidenciam situações de enunciação distintas.

DEUSDARÁ e ROCHA, 2001, p. 122

A HE mostrada torna este embate visível na construção dos enunciados. Já na HE constitutiva, as relações são mais discursivas, encontradas na profundidade dos discursos que originam estes enunciados. Carregam-se de ideologia, mas não se mostram de maneira marcada.

No artigo de Brito et al (2017) é mencionada a alusão como um processo formador da $\mathrm{HE}$ enunciativa em textos. Mais ainda: como estratégia argumentativa a dialogar com outros discursos. Textualmente, afirmam que "opera-se uma alusão quando se faz uma espécie de referência por pistas; não se diz claramente a que se está referindo, mas se fazem insinuações contextuais" (Brito et al., 2017, p. 25). Não há marcadores textuais, mostrados ou não, no processo alusivo. Os autores usam suportes vários: charges, posts em redes sociais e outros materiais como corpus para indicar as referências que compõem o processo de aludir a um outro discurso, a um outro elemento. Essas referências, no artigo estudado, são vagas ou mesmo indiretas, demandando conhecimento prévio para que o interlocutor as assimile a contento. A alusão delimita a distância entre sujeitos, por isso se arrisca a ser exclusão ou conveniência.

De Mesquita e Rosa (2010) cotejam a noção de heterogeneidade constitutiva com a noção de interdiscurso, "corroborando que todo discurso é construído no processo de incorporação de outros discursos, pré-construídos, produzidos em seu exterior" (Authier-Revuz, 2010, p. 132). Dialoga e complementa com o que pontua Authier-Revuz (1990) sobre este mesmo conceito: ela refere-se a "processos de representação, num discurso, de sua constituição" (Authier-Revuz, 1990, p.32).
Apoiando-se no conceito de alteridade ao utilizar a HE como ferramenta de análise, Araújo e Gonzaga (2017) que o outro está presente constitutivamente no sujeito e discurso - questiona ainda o sujeito como fonte autônoma do dizer. As relações de alteridade delimitam posições discursivas, materializam embates com o já-dito. Posicionamentos distintos, referenciados por formações historicamente e discursivamente distintas são linguisticamente materializados em enunciados. Essas relações, posicionamentos e formações discursivas utilizaram a heterogeneidade constitutiva como forma de perceber estes movimentos de alteridade.

\section{CONCLUSÃO}

Em todo o corpus pesquisado para este artigo, nota-se em grande parte dos trabalhos que a $\mathrm{HE}$ tem sido mostrada como um campo de estudo dentro da Análise do Discurso de linha Francesa, a partir de Michel Pêcheux e sua obra "Semântica e Discurso", embora existam pesquisas que tratem este conceito como algo mais abrangente, até por dialogar com outras áreas fora do campo dos estudos da linguística aplicada. Como a ideia neste trabalho era analisar como a HE tem sido aplicada na academia brasileira, foi feito o afunilamento das pesquisas de corpus em materiais em que utilizaram esta referência como aporte fundamental de trabalho.

Dentro deste panorama, a percepção que fica é que a HE oferece possibilidades de estudo muito interessantes e abrangentes, seja como ferramenta de suporte para análise e contextualização de enunciados ou sujeitos ou mesmo como campo de estudo com vigo próprio. Seja por marcar ou não elementos linguísticos, dentro do que se chama heterogeneidade mostrada, ou mesmo apontar relações entre enunciados, sujeitos e discursos na heterogeneidade marcada, o que temos é um postulado com definições claras e que, como em sua própria gênese conceitual, 
mostra-se em constante relação dialógica com o que é produzido. Organiza a sinfonia de vozes que cobrem os enunciados, portanto, como o próprio nome aponta, o conceito é heterogêneo justamente por seu caráter polifônico. As formas de representação do sujeito que se mapeiam e estudam servem não só para compreender a distinção entre o emissor e o discurso, mas fundamentalmente entender os mecanismos que estão por trás das formações textuais dos discursos emitidos nas mais diversas situações sociais possíveis. É, portanto, forma de contribuir para ver e entender o mundo.

Todos os autores declararam não haver qualquer potencial conflito de interesses referente a este artigo.

\section{REFERÊNCIAS}

AUTHIER-REVUZ, J. Heterogeneidades enunciativas. Cadernos de estudos linguísticos, 19. Campinas, IEL. 1990.

Heterogeneidade mostrada e heterogeneidade constitutiva: elementos para uma abordagem do outro no discurso. In: Entre a transparência e a opacidade: um estudo enunciativo do sentido. Porto Alegre: EDIPUCRS, 2004. p. 11-80.

- A representação do discurso outro: um campo multiplamente heterogêneo. Calidoscópio, v. 6, n. 2, p. 107-119, 2008.

BRITO, Mariza Angélica Paiva; FALCÃO, Maria Dayanne Sampaio; DE SOUZA SANTOS, José Elderson. APELO A UM EXTERIOR: AS ALUSÕES COMO ESTRATÉGIAS ARGUMENTATIVAS/THE APPEAL TO AN EXTERIOR: ALLUSIONS AS ARGUMENTATIVE STRATEGIES. Revista de Letras, v. 2, n. 36, 2017. CAPES - Coordenação de Aperfeiçoamento de Pessoal de Nível Superior. Sobre a Capes. Disponível em:

<https://www.capes.gov.br/pt/acessoainformacao/per guntas-frequentes/sobre-a-capes/7473-sobre-acapes>. Acesso em: 13/07/2019

DE ALBUQUERQUE SANT'ANNA, Vera Lúcia. Discurso relatado como estratégia organizadora da notícia. The ESPecialist, v. 24, 2003.
DE ALMEIDA FERREIRA, Norma Sandra. As pesquisas denominadas" estado da arte. Educação \& sociedade, v. 23, p. 257, 2002.

DE ARAÚJO GONZAGA, Juliane. A interincompreensão gera polêmica: alteridade e heterogeneidade nos discursos das cantoras Anitta e Pitty sobre comportamento sexual feminino. Revista de Estudos da Linguagem, v. 25, n. 1, p. 381-409, 2017.

DE MESQUITA, Diana Pereira Coelho; ROSA, Ismael Ferreira. As heterogeneidades enunciativas como aporte teórico-metodológico para a Análise do Discurso de linha francesa. Revista Veredas, v. 14, n. 2, 2010 .

DEUSDARÁ, Bruno; ROCHA, Décio. Vozes em embate na mídia de informação e produção da objetividade: polêmicas em torno da precarização do trabalho na escola. DELTA: Documentação e Estudos em Linguística Teórica e Aplicada, v. 27, n. $1,2011$.

DOMINGUEZ, Michelle. Do sistema à ação, do homogêneo ao heterogêneo: movimentos fundantes dos conceitos de dialogismo, polifonia e interdiscurso. Bakhtiniana. Revista de Estudos do Discurso, v. 8, n. 1, p. 5-20/Eng. 5-21, 2013.

MARTINS, Marci Fileti. Divulgação científica e a heterogeneidade discursiva: análise de "Uma breve história do tempo" de Stephen Hawking. Linguagem em (Dis) curso, v. 6, n. 2, p. 231-240, 2006.

MACEDO, Ezequiel Bezerra Izaias de. O eu e os outros: uma análise da heterogeneidade enunciativa do sujeito na produção acadêmica / Ezequiel Bezerra Izaias de Macedo. - Recife: O Autor, 2016.

PAULA, Orlando de. Noções de coesão na visão de formandos em Letras. 2009. Tese de Doutorado. Universidade de São Paulo.

- O discurso de formandos do curso de Letras: "Falta coesão, falta coerência no texto de uma menina de 10 anos!" Fórum Linguístico, v. 11, n. 4, p. 444456, 2014.

ROMANOWSKI, Joana Paulin; ENS, Romilda Teodora. As pesquisas denominadas do tipo" estado da arte" em educação. Revista diálogo educacional, v. 6 , n. 19, p. 37-50, 2006.

SEVERINO, Antônio Joaquim. Metodologia do trabalho científico. Cortez editora, 2002. 